\title{
The Vienna declaration on nutrition and non-communicable diseases
}

\author{
Time to look upstream
}

\author{
Debbie A Lawlor professor of epidemiology ${ }^{1}$, Neil Pearce professor of epidemiology and biostatistics ${ }^{2}$
}

${ }^{1} \mathrm{MRC}$ Integrative Epidemiology Unit at the University of Bristol, School of Social and Community Medicine, Bristol BS8 2BN, UK; ${ }^{2} \mathrm{Centre}$ for Global NCDs, London School of Hygiene and Tropical Medicine, UK

\begin{abstract}
Vienna is sometimes called the "city of dreams" because of its central role as the birthplace of psychoanalysis. Now it is playing a central role in a very different type of health problem, that of non-communicable diseases. On 5 July the Vienna declaration was launched at the World Health Organization ministerial conference on non-communicable diseases in the context of Health 2020. ${ }^{1}$ Of particular concern was "the rapid rise of overweight and obesity, especially in children."
\end{abstract}

However, whether this declaration will result in effective action is unclear. It highlights the need for a multiagency approach and high level political support, but the main emphasis is on downstream (individual level) solutions and individual responsibility for lifestyle change.

Children (and adults) become fatter because they consume more energy than they expend. ${ }^{2}$ Genetics also plays a role, but genetic factors cannot be responsible for the recent epidemic in overweight and obesity. ${ }^{3}$

Government recommendations increasingly acknowledge the varied ways people can achieve healthy levels of physical activity, but they tend to emphasise leisure time physical activities, such as sport, running, and going to the gym for adults, and school time activities for children. ${ }^{45}$ However, such activity accounts for only a small part of total physical energy expenditure. ${ }^{5}$ The effect of increasing childhood activity through compulsory physical activity lessons is small and may not result in sustained change. In recent decades, energy expenditure has decreased markedly because of changes to the urban environment. These include urban design, safety concerns (which discourage children from walking to school), the rise of the car (which causes further concern about the safety of children walking), and the near demise of public transport. ${ }^{67}$

Excessive energy intake among children is also driven by upstream structural factors. These include the widespread availability of cheap energy dense foods, including in school vending machines, targeting of children by the manufacturers of these foods, and ever increasing portion sizes of foods and sugary drinks. ${ }^{8}$
Given these societal influences, it is not surprising that childhood obesity follows similar patterns of transmission to those seen for infectious diseases. ${ }^{9}$ This does not mean that we should give up trying to persuade people to change their lifestyles, but it does mean that this is not enough. Interventions aimed at educating people to make healthier choices are generally of limited effectiveness and must be renewed with each generation, which is expensive and time consuming. ${ }^{10}$ Such interventions also tend to exacerbate health inequalities. By contrast, upstream changes are potentially longer lasting and more equitable. Changes to the environment-which make physical activity and a healthy diet once again part of daily life rather than a lifestyle choice-are needed.

The wide variation in the prevalence of childhood overweight between European countries is notable (figure). This variation remains even if the comparisons are confined to surveys conducted in the five most recent years (2007-12), which used direct measurements and International Obesity Task Force (IOTF) criteria. The variation does not follow patterns related to wealth, climate, or culture, and it suggests that the lowest levels could be seen across the whole of Europe.

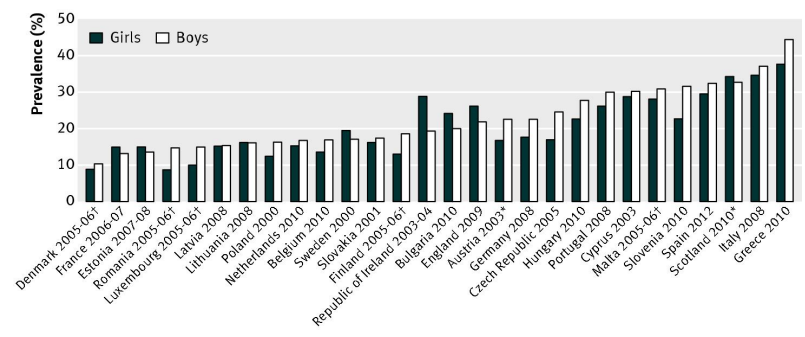

Prevalence of childhood overweight in Europe. Data obtained from the International Association for the Study of Obesity website. ${ }^{11}{ }^{*}$ Childhood overweight or obesity defined by national reference chart centiles; for all other countries International Obesity Task Force criteria were used. †Using body mass index based on self or parental report of weight and height; for all other countries weight and height were measured 
The member states of the European Union must work together on changing the urban environment to one that supports physical activity now and for generations to come. The way that food is produced, sold, and marketed must also change, so that eating a healthy balanced diet is affordable and the norm. The Vienna Declaration notes the "pervasive effects" of the current global economic crisis "on the affordability and accessibility of a healthy diet" and how this might widen social inequality. At least as big a threat is the political response to the economic crisis, which has included severe cuts to public spending in many EU member states.

Politicians across the EU are generally reluctant to support environmental changes that might threaten the car and certain food industries. Where they have attempted to direct industry it has largely been on a voluntary basis. After pressure from voluntary agencies, public health practitioners, and WHO, the governments of many EU member states made voluntary agreements with the food industry regarding control of marketing of foods high in energy, fat, sugar, and salt to children. ${ }^{12}$ However, evidence suggests that these voluntary agreements are selective, difficult to evaluate, and often breached. ${ }^{12}$ Furthermore, many voters are reluctant to change their current car usage or support the so called nanny state.

For these reasons, we are unlikely to win these arguments on health grounds alone. The Vienna declaration argues that most premature deaths from non-communicable diseases could be prevented if influential policies were adopted in sectors other than health, rather than trying to tackle the problem through health policy alone. However, in most countries, other government agencies have resisted attempts from ministries and departments of health to influence their policies.

Perhaps we need to recognise that health is just a part of the policy mix, and that people may support healthy environmental changes for non-health reasons. For example, most Londoners probably would not have supported the congestion charge because it would improve their health by getting them out of their cars, but they would support it because it makes London a nicer place to live. More generally, most people won't vote to be lectured about healthy lifestyles, or to have their lifestyle options restricted solely for some potential future health benefit. However, they will vote for safe liveable neighbourhoods and cities, in which it is easy to walk or cycle to work or school, and in which locally produced foods are widely available and affordable. Some lateral thinking is needed.

Competing interests: We have read and understood the $B M J$ policy on declaration of interests and declare the following interests: None.

Provenance and peer review: Commissioned; not externally peer reviewed.

1 Vienna Declaration on Nutrition and Noncommunicable Diseases in the Context of Health 2020. WHO Ministerial Conference on Nutrition and Noncommunicable Diseases in the Context of Health 2020. 2013.

2 Han JC, Lawlor DA, Kimm SYS. Childhood obesity. Lancet 2010;375:1737-48.

3 Lindgren CM, Heid IM, Randall JC, Lamina C, Steinthorsdottir V, Qi L, et al. Genome-wide association scan meta-analysis identifies three Loci influencing adiposity and fat distribution. PLoS Genet 2009;5:e1000508.

4 Dobbins M, Husson H, DeCorby K, LaRocca RL. School-based physical activity programs for promoting physical activity and fitness in children and adolescents aged 6 to 18 . Cochrane Database Syst Rev 2013;2:CD007651.

5 Hu FB. Obesity epidemiology. Oxford University Press, 2008.

6 Frumkin H, Frank L, Jackson R. Urban sprawl and public health: designing, planning and building for healthy communities. Island Press, 2004.

7 Bain C. Commentary: What's past is prologue. Int J Epidemiol 2006;35:16-7.

8 Cummins S, Macintyre S. Food environments and obesity - neighbourhood or nation? Int J Epidemiol 2006;35:100-4

9 Christakis NA, Fowler $\mathrm{JH}$. The spread of obesity in a large social network over 32 years. N Engl J Med 2007;357:370-9.

10 Ebrahim S, Davey Smith G. Exporting failure? Coronary heart disease and stroke in developing countries. Int J Epidemiol 2001;30:201-5.

11 International Association for the Study of Obesity. Global overweight in children. www. iaso.org/resources/obesity-data-portal/resources/tables/.

12 Lobstein T, Parn T, Aikenhead A. A junk-free childhood: responsible standards for marketing foods and beverages to children. A briefing paper from the StanMark project of the International Association for the Study of Obesity. 2011. www.iaso.org/site_media/ uploads/IASO_food_marketing_report_30_June_2011.pdf.

Cite this as: BMJ 2013;347:f4417

(c) BMJ Publishing Group Ltd 2013 